\title{
Adult-Child Discourse: Developmental Interaction Between Information Processing and Linguistic Knowledge ${ }^{1}$
}

Lois Bloom, Lorraine Rocissano, and Lois Hood Teachers College, Columbia University

CitATiOn: Bloom, L., Rocissano, L., and Wootten, J. (1982). Adult-Child Discourse: Developmental Interaction Between Information Processing and Linguistic Knowledge. Cognitive Psychology, 8, 521-551. Reprinted in Bloom, L. (1991). Language development from two to three. New York: Cambridge University, pp. 437-471.

\begin{abstract}
The discourse interaction between adult and child was examined in terms of the content of their utterances, and the linguistic and contextual relations between their messages, in order to investigate how children use the information from adults' input sentences to form contingent responses. The analyses described were based on longitudinal data from four children from approximately 21 to 36 months of age. Categories of child discourse, their development and their interactions with aspects of prior adult utterances form the major results of the study. Child utterances were identified as adjacent (immediately preceded by an adult utterance), or as nonadjacent (not immediately preceded by an adult utterance). Adjacent utterances were either contingent (shared the same topic and added new information relative to the topic of the prior utterance), imitative (shared the same topic but did not add new information), or noncontingent (did not share the same topic). From the beginning, adjacent speech was greater than nonadjacent speech. Contingent speech increased over time; in particular, linguistically contingent speech (that expanded the verb relation of the prior adult utterance with added or replaced constituents within a clause) showed the greatest developmental increase. Linguistically contingent speech occurred more often after questions than nonquestions. The results are discussed in terms of how the differential requirements for processing information in antecedent messages is related to language learning.
\end{abstract}

In the beginning of language development, a child's major source of information for formulating messages is nonlinguistic; young children talk primarily about what they see and do. One of the goals of language development, however, is the ability to obtain information from a prior linguistic signal, relate that information to existing knowledge, and form a contingent message. In the present study, discourse between adults and children was observed, and the content of successive adult and child utterances was described in terms of the semantic and formal relations between their messages. In this way it was possible to determine to what extent, and how, the four children in this study learned to use the information represented in input sentences for formulating their own messages, in their language development from 2 to 3 years of age.

Three sorts of interaction studies in language development are relevant to the development of conversational discourse in child language. Most studies have been studies of input only, in that they have focused on the form of adult speech to children in order to describe the model of speech from which children learn language, for example, Baldwin and Baldwin (1973), Broen (1972), Phillips (1973), Siegel (1963), and Snow (1972). Other studies have been concerned with the conventions of conversation, whereby matters of pacing, pausing, turn

${ }^{1}$ This study was supported by Research Grant HD 03828 from the National Institute of Child Health and Development; Fellowship F1-MH-30,001 from the National Institute of Mental Health, United States Public Health Service; and Research Grant Soc 74-28126 from the National Science Foundation to Lois Bloom. The study was published originally in Cognitive Psychology, 8, 521-551; reprinted in Bloom, L. (1991). Language development from two to three, New York: Cambridge University, pp. 437-471; and reformatted for this digital version with slight changes in organization and minor text editing. 
taking, initiating, and terminating are controlled by the participants and serve various functions, for example, Dittman (1972), Garvey and Hogan (1973), and Keenan (1974a). The studies most relevant to the research reported here are those that have looked at the aspects of form and content shared by reciprocal messages, such as the studies by Keenan (1974b); Seitz and Stewart (1975); Shapiro, Roberts, and Fish (1970); and Soderbergh (1974); and the study of the function of imitation for lexical and grammatical learning reported in Bloom, Hood, and Lightbown (1974).

The general question addressed in the research reported here had to do with the source of the information coded in children's messages. There are two sources of information for coding in language: the conceptual representation of experience in memory-the knowledge that the child has of objects and events in the world-and the situation in which the speech event occurs. The particular question addressed in the present study had to do with the ability to use that information in the situation that is presented to the child in the form of an utterance from someone else, for formulating a contingent message. After describing the procedures of the study, the development of discourse will be described in terms of (1) the extent to which children's speech was contingent on prior adult messages, (2) the semantic and formal interactions between adult speech and contingent child speech, and (3) the influence of the child's linguistic knowledge on these interactions between adult and child speech.

\section{SUBJECTS AND PROCEDURES}

The four children in this study-Eric, Gia, Kathryn, and Peter-were born in the 196os, the first-born children of white, college-educated parents who lived in university communities in New York City. Their parents were native speakers of American English and their mothers were their primary caregivers. They were chosen as subjects with these qualifications in what turned out to be, in retrospect, a naive effort to come up with a 'homogeneous' population. Since parent education, birth order, and economic differences among children had been found to be sources of individual differences in speech and language in other studies, these were the minimal 'controls' that seemed feasible to ensure that the children would be similar in their language learning. ${ }^{2}$

Eric, Gia, and Kathryn were each visited in their homes for approximately eight hours over several days, every six weeks, by Lois Bloom; Peter was visited for approximately six hours every three weeks by Lois Hood and Patsy Lightbown. The visits occurred in the context of their daily activities and informal play with a familiar adult (the investigators) and, less often, with their mothers. The same or similar toys were brought to all the sessions, for the different children and for each child, in an effort to establish consistency in the home contexts among the children and over time. The observations were audio recorded, and the transcriptions included all speech by child and adult, along with descriptions of nonlinguistic context and behavior. ${ }^{3}$

For the purpose of this study, the longitudinal data were sampled with a consecutive sample (CS) of 400 utterances from each of the children, at each of three times when the mean length of utterance (MLU) coincided with the periods in language development defined by Brown (1973) as Stage 1, MLU < 2.0; Stage 2, MLU 2.0-2.75 and Stage 5, MLU 3.5-4.0. In these three stages, mean length of utterance progressed from approximately 1.3 to 4.0 morphemes, and the children progressed from approximately 21 to 36 months of age.

The analyses reported here began with samples of 200 consecutive utterances from each child at each time. A second sample of 200 consecutive utterances from each child at each time was analyzed afterwards in order to test the validity of the first analysis. Although there was some variation between two samples from the same

2 NotE. However, see Bloom (1992) for a later appraisal of this decision.

3 The procedures for data collection and transcription are described in greater detail in Bloom (1970, pp. 234-9). See also, Bloom, Lightbown, and Hood (1974) and conventions for transcription of child language recordings, App. A, in Bloom \& Lahey (1978). The speech samples from Eric, Gia, and Kathryn were collected and transcribed by Lois Bloom. The speech samples from Peter were collected and transcribed by Lois Hood and Patsy Lightbown, who took turns interacting with Peter and taking notes on the situational context and behavior. The transcriptions of the Eric, Gia, Kathryn, and Peter data are stored for access by other researchers in the Special Collections at the Gottesman Memorial Libraries, Teachers College, Columbia University; transcripts of the Peter data are also part of the CHILDES database, the Child Language Data Exchange System, Carnegie-Mellon University. 
corpus in certain instances, the interactions that form the results of the study were the same in all instances with both of the 200 utterance samples from each child at each time. Accordingly, the results for the two samples combined for each child at each time are reported here.

Child utterances were examined in order to determine, first, whether the utterance followed an adult utterance (adjacent speech) and, then, whether the relationship between an adjacent child utterance and a prior adult utterance was a semantic relation, with continuity of meaning as determined by nonlinguistic and linguistic contexts and, also, a formal relation, with lexical or structural continuities. The child discourse categories that were observed as a result of these levels of analysis, and their interaction, form the results of the study.

\section{RESULTS}

\section{Adjacent and Nonadjacent Speech}

Whether or not the children took account of a prior adult message for formulating their own message depended, in the first place, upon whether or not an adult said something before the child said something. The first distinction, then, was between speech that was and was not adjacent.

The factor that distinguished between adjacent and nonadjacent speech was pause time. If a definite pause occurred between a child utterance and a preceding adult utterance, then the child utterance was considered not adjacent to the adult utterance. If there was less than a definite pause or no pause between a child utterance and a preceding adult utterance, then the child utterance was considered as occurring within the space of the adult utterance and so adjacent to the adult utterance. The judgment of pause time was subjective and determined from the description of the contexts of events as recorded in the transcriptions. In order to test the reliability of the decisions that utterances were or were not adjacent to prior adult utterances, judgments were made by two independent observers of 150 of the utterances ( 25 utterances from each of two children at each stage). The agreement of the two independent observers with the original judgment of the investigators was .94 and .86 at Stage 1; .92 and .92 at Stage 2; and .94 and .98 at Stage 5. The question remains whether there were nonadjacent utterances that were actually related to preceding adult utterances and separated only arbitrarily by subjective pause time. The intent, however, was to determine the extent to which child utterances occurred in the time/space context of a prior adult utterance, and not to determine any and all possible relations between child utterances and all previous adult utterances. Accordingly,

Adjacent speech consisted of those child utterances that occurred after an adult utterance. Nonadjacent speech consisted of those child utterances that occurred without a previous adult utterance or with a definite pause after a previous adult utterance. For example:
(Adult and child sit on floor, child picks up block)
(i) here a block.
Let's build a bridge.
(ii) a big bridge.
(Child and adult building; child picking up a block)
(iii) this block.

In the above examples (i) "here a block" is nonadjacent, having occurred without a previous adult utterance, and (ii) "a big bridge" is adjacent to the adult utterance "Let's build a bridge." The third child utterance (iii)

"this block," is nonadjacent, having occurred after a pause during which there was also a shift of focus. There was no independent means of knowing whether (ii) "a big bridge" would have occurred if the adult utterance "Let's build a bridge" had not occurred, or if (iii) "this block" would have occurred if the adult utterance "Let's build a bridge" had not also occurred before it. The distinction between adjacent and nonadjacent speech simply identified those child utterances that occurred in the context of an immediately previous adult utterance.

One might suppose that adjacent speech was greater than nonadjacent speech because of the frequency of adult speech; with many utterances from the adult it might seem that few opportunities for nonadjacent speech from the child would occur. To explore this possibility, the average frequencies of adult and child speech per hour were compared at all three stages, and the frequency of child speech is plotted against the frequency of adult speech for each child in Figure 1. Both adult and child speech increased from Stage 1 to Stage 5, and in 10 of the 12 
samples, child speech was more frequent than adult speech; adult speech was more frequent in only the first samples from Kathryn and Eric. Although the absolute frequencies of both adult and child speech increased, the increase in adult speech was not reflected in a proportional increase in adjacent child speech (see Table 1). This suggests that the high proportion of adjacent speech was not a function of how frequently the adults talked.

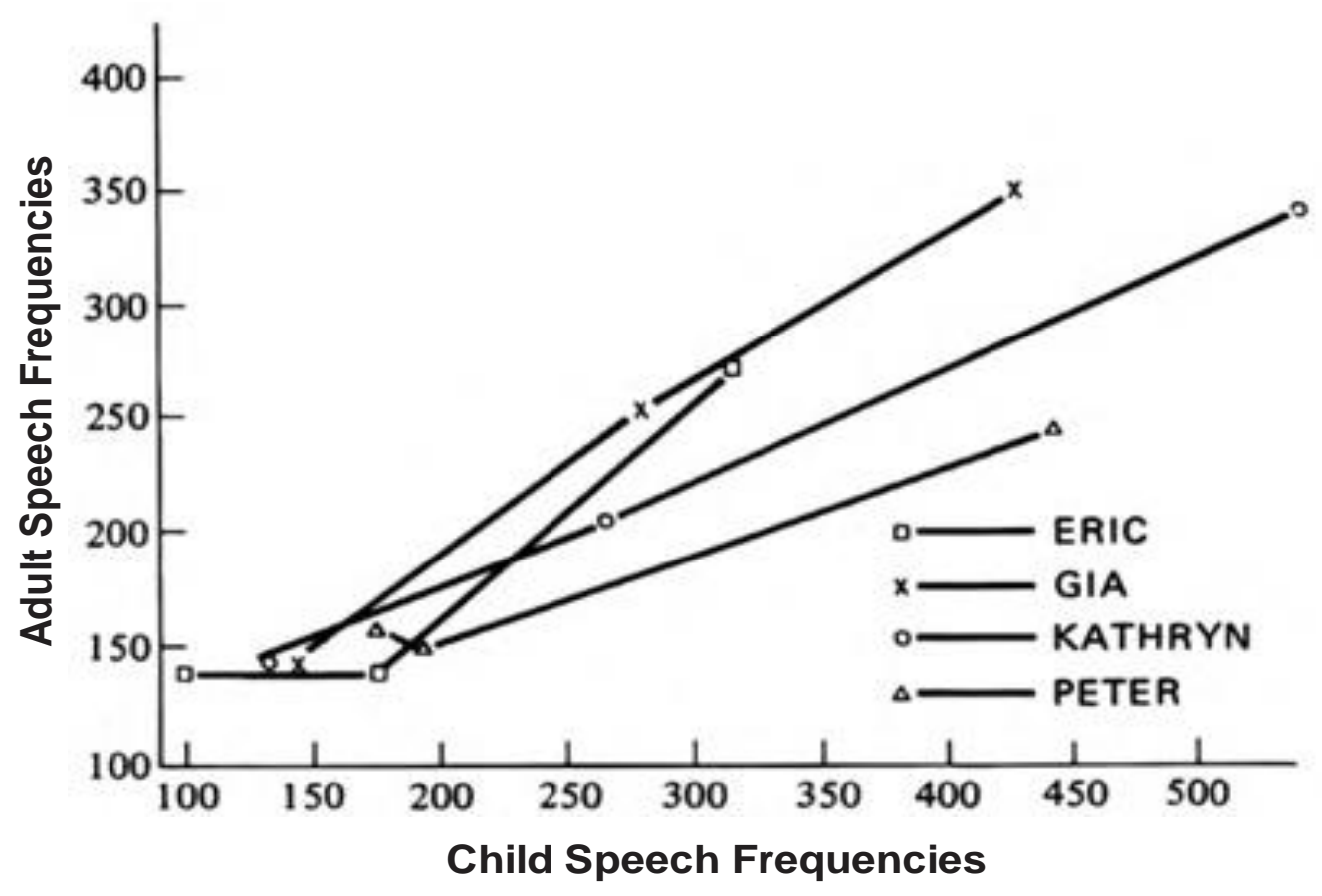

Figure 1. Frequency of adult and child speech, average number of utterances per hour. 4

\section{Children's Adjacent Speech}

Three kinds of adjacent child speech were observed: contingent, noncontingent, and imitative speech (Figure 2). Two factors distinguished among these three: first, whether a child utterance shared the topic of the prior adult utterance and, second, if both utterances shared the same topic, whether the child utterance added new information relative to the topic of the prior utterance. All utterances that added new information shared the same topic, but not all utterances that shared the same topic also added new information. The agreement of two independent observers with the original judgment made by the investigators of kinds of adjacent speech was .93 and .95 at Stage $1 ; .91$ and .89 at Stage 2; and .98 and .96 at Stage 5 .

\footnotetext{
4 In computing the frequency of adult speech, clusters of adult utterances unified by topic and not separated by pauses-so that the child could not have responded, for example, the series of utterances ["They'll be right back. They'll come back soon. They went to buy the paper"] were counted together as a turn for determining frequency and interpreting subsequent child speech. Similarly, successive child utterances unified by topic were counted only once.
} 


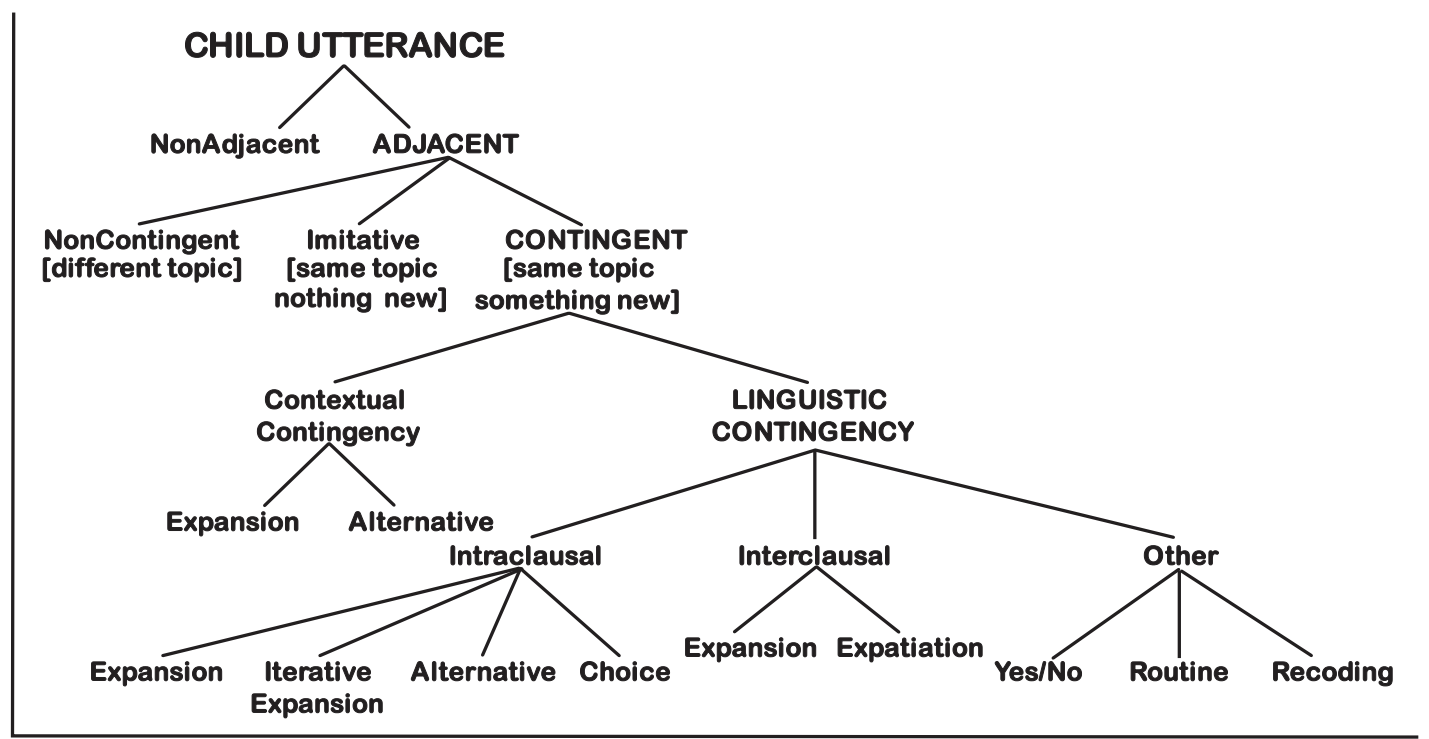

Figure 2. Categories of Child Discourse

Noncontingent speech consisted of those adjacent child utterances that did not share the same topic as the preceding adult utterances, for example:

(1) E (Stage 2)

Alright, put the light on.

cookie.

(2) K (Stage 2)

(looking out window)

Where are the children?

(climbing off window ledge) wanna get down.

Imitative speech consisted of adjacent child utterances that shared the same topic with the preceding utterance but did not add information; that is, all or part of the preceding utterance was repeated with no change, for example:

(3) $\mathrm{K}$ (Stage 1)

Take your shirt off.

shirt off.

(4) P (Stage 1)

She might pinch her fingers.

pinch her fingers.

Contingent speech consisted of those adjacent child utterances that both (1) shared the same topic with the preceding adult utterance and (2) added information to it, for example:

(5) E (Stage 2)

I see two.

I see two bus come here.

(6) K (Stage 2)

I'm gonna build a high house.

I wanna build a high house too.

The proportion of contingent, noncontingent, and imitative utterances in the CS are presented in Figure 3 for the four children combined and in Table 1 for the individual children at each stage. Contingent speech increased developmentally, and imitation decreased for the four children; except for Gia, noncontingent speech decreased. When the nonadjacent speech was discounted, the average proportion of just the adjacent speech from the four 
children that shared the topic of a prior adult utterance (that is, contingent and imitative speech) increased from .56 at Stage 1, to .67 at Stage 2, to .76 at Stage 5. Speech that was contingent (that shared the topic and added new information) increased from .31 at Stage 1, to .57 at Stage 2, to .73 at Stage 5. When the nonadjacent speech was discounted, the average proportion of just the adjacent speech from the four children that shared the topic of a prior adult utterance (that is, contingent and imitative speech) increased from .56 at Stage 1, to .67 at Stage 2, to .76 at Stage 5. Speech that was contingent (that shared the topic and added new information) increased from .31 at Stage 1, to .57 at Stage 2, to .73 at Stage 5 .

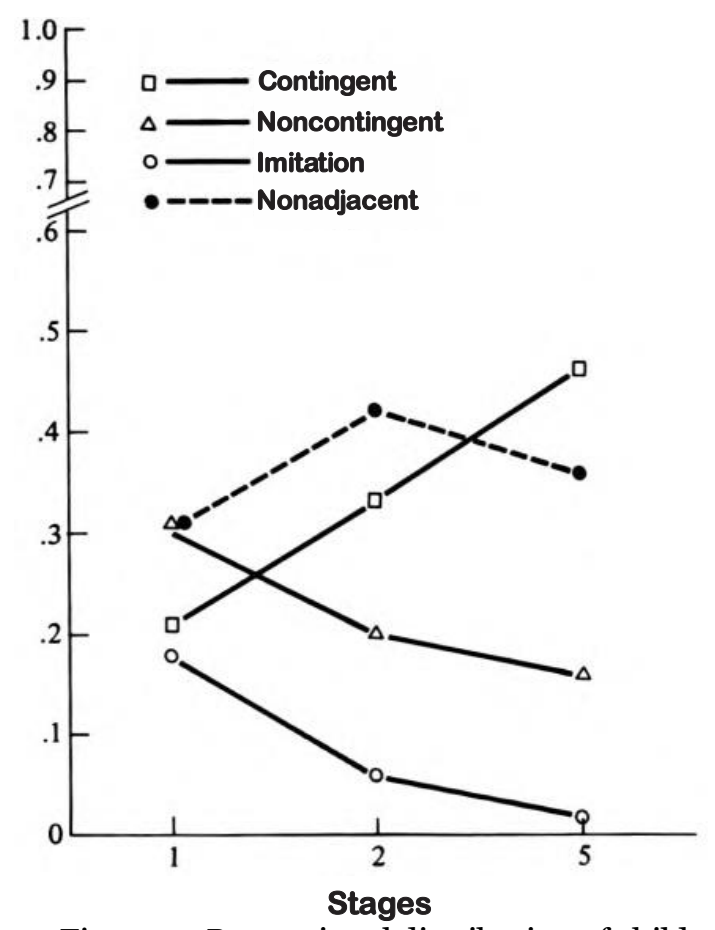

Figure 3. Proportional distribution of child utterances in categories of child discourse for the four children combined. 5

5 In the figures that present the combined data from the four children $(N=1,600$ utterances at each stage), the stages along the abscissa represent discrete points in time, so that the lines between points are not continuous functions. 
Table 1. Distribution of Adjacent and Nonadjacent Utterances ${ }^{\mathrm{a}}$

\begin{tabular}{|c|c|c|c|c|c|c|c|}
\hline \multirow[b]{2}{*}{ Child, Stage } & \multirow[b]{2}{*}{ MLU } & \multirow[b]{2}{*}{ Age } & \multicolumn{4}{|c|}{ ADJACENT SPEECH } & \multirow[b]{2}{*}{$\begin{array}{c}\text { NON- } \\
\text { ADJACENT }\end{array}$} \\
\hline & & & Contingent & $\begin{array}{c}\text { Non- } \\
\text { Contingent }\end{array}$ & Imitative & Total & \\
\hline \multicolumn{8}{|l|}{ Eric } \\
\hline 1 & 1.19 & 20,2 & .28 & .31 & .12 & .71 & .29 \\
\hline 2 & 2.63 & 25,1 & .29 & .23 & .05 & .56 & .44 \\
\hline 5 & 3.83 & 36,0 & .52 & .18 & .04 & .74 & .26 \\
\hline \multicolumn{8}{|l|}{ Gia } \\
\hline 1 & 1.12 & 19,2 & .24 & .23 & .17 & .64 & .36 \\
\hline 2 & 2.30 & 25,2 & .45 & .09 & .01 & .55 & .45 \\
\hline 5 & 4.14 & 36,0 & .53 & .25 & - & .78 & .22 \\
\hline \multicolumn{8}{|l|}{ Kathryn } \\
\hline 1 & 1.32 & 21,0 & .23 & .30 & .23 & .75 & .25 \\
\hline 2 & 2.83 & 24,2 & .33 & .25 & .09 & .67 & .33 \\
\hline 5 & 4.23 & $35 \cdot 3$ & .39 & .13 & .01 & .53 & .47 \\
\hline \multicolumn{8}{|l|}{ Peter } \\
\hline I & 1.41 & 23.1 & .10 & .39 & .18 & .67 & .33 \\
\hline 2 & 2.62 & 26,1 & .24 & .21 & .09 & .54 & .46 \\
\hline 5 & $3-70$ & 38,0 & .42 & .09 & .02 & .53 & .47 \\
\hline
\end{tabular}

${ }^{a} n=400$ utterances for each child at each stage.

The adult speech the children heard consisted of investigator speech more often than mother speech. In order to determine whether this variable was important, the proportions of imitative, contingent, and noncontingent child speech were compared in the two contexts of mother and investigator speech for the four children at Stages 1 and 2. There were 24 comparisons (four children, at two stages, with three discourse categories), and there was no significant difference (by chi square tests of proportions) between mother and investigator in 20 comparisons. In Stage 1, Peter used more imitative speech with his mother (chi square $=4.968, p<.05$ ); in Stage 2, Gia used more imitative and noncontingent speech with her mother (chi square $=5.516$ and 4.338 , respectively, $p<.05$ ) and more contingent speech with the investigator (chi square $=9.926, p<.01$ ).

\section{Linguistic and Contextual Contingency}

Child utterances were distinguished according to whether and how the children used information in an adult message for formulating their own messages. There were different kinds of contingency when a child produced an utterance that shared the same topic as a prior adult utterance, and the proportional frequencies of utterances in each of these categories of topic-related speech are presented in Table 2. 
Table 2. Proportions of Utterances in Categories of Topic-Related Discourse

\begin{tabular}{|c|c|c|c|c|c|c|c|c|c|}
\hline \multirow[b]{2}{*}{$\begin{array}{l}\text { Child, } \\
\text { Stage }\end{array}$} & \multirow[b]{2}{*}{$\mathrm{N}^{\mathrm{a}}$} & \multicolumn{8}{|c|}{ CONTINGENT SPEECH } \\
\hline & & Yes-No & $\begin{array}{c}\text { Social } \\
\text { Routine }\end{array}$ & Recoding & $\begin{array}{l}\text { Self-Expa } \\
\text { nsion and } \\
\text { Recoding }\end{array}$ & Expansion & Alternative & Expatiation & Imitation \\
\hline \multicolumn{10}{|l|}{ Eric } \\
\hline 1 & 162 & .24 & .01 & .03 & .01 & .38 & .04 & - & .30 \\
\hline 2 & 147 & .13 & - & .05 & - & .46 & .12 & - & .15 \\
\hline 5 & 223 & .23 & - & .04 & .05 & .56 & .05 & - & .08 \\
\hline \multicolumn{10}{|l|}{ Gia } \\
\hline I & 167 & .05 & - & .05 & - & .46 & .01 & - & .42 \\
\hline 2 & 186 & .45 & .01 & .03 & .01 & .36 & .13 & - & .02 \\
\hline 5 & 213 & .27 & - & .04 & .02 & .51 & .13 & .03 & .01 \\
\hline \multicolumn{10}{|c|}{ Kathryn } \\
\hline 1 & 181 & .13 & - & .04 & .01 & .31 & .03 & - & .50 \\
\hline 2 & 167 & .23 & - & .07 & .01 & .43 & .06 & - & .22 \\
\hline 5 & 162 & .20 & - & .02 & .05 & .54 & .09 & .05 & .04 \\
\hline \multicolumn{10}{|l|}{ Peter } \\
\hline 1 & 113 & .01 & - & .09 & - & .16 & .10 & - & .65 \\
\hline 2 & 130 & .35 & .02 & .05 & .03 & .22 & .07 & - & .26 \\
\hline 5 & 176 & .32 & - & .05 & .06 & .44 & .06 & .02 & .06 \\
\hline
\end{tabular}

$a_{n}=$ number of contingent and imitative utterances, at each stage for each child.

Most simply, the child could respond yes or no or produce some sort of social routine like thank you or bye-bye. Social routines were relatively rare. Yes and no as single-word utterances were variable, both longitudinally for individual children and among the children, and were difficult to evaluate. It was not always clear the words were used appropriately since they often appeared to be a set response and provided little insight into how the children used the information in a prior adult messages. For these reasons, a child's yes or no was ignored unless it was followed by a child utterance that shared topic.

Recodings were child utterances that repeated part or all of the prior adult utterance and changed its form without adding to or altering its meaning. Recodings accounted for less than .10 of the topic-related speech in each sample. Recodings at Stage 1 were predominantly shifts from the nominal coding of predicate objects (in the adult utterance) to pronouns (in the child utterance). At Stage 2, anaphoric deictic recoding began, with pronominal shift for agents, from you (in adult utterance) to $I$ (in child utterance). Finally, at Stage 5, anaphoric deixis was extended to pronoun shift for objects, this and that, and place, here and there. In addition, there were self-expansions and self-recodings that were contingent on an adult acknowledgment (for example, "hm, you do" or "oh") of a child's prior utterance. ${ }^{6}$

The remaining categories were most important developmentally (examples to follow in the subsequent section): the linguistically contingent utterances that were expansions (added information about the topic of a prior utterance), alternatives (added information by opposing an aspect of the topic in the prior utterance), or

6 When a child utterance followed an adult acknowledgment but changed topic, it was counted as nonadjacent. Also, sequences in which the adult asked the child to repeat because the child had not been heard or understood, for example, by saying "What?" or "What did you say?" were not included in the CS. 
expatiations (added information to the prior utterance and introduced another, related topic). As can be seen in Table 2, expansions, where the child added to the adult utterance in several ways, increased. Expatiations were a late development at Stage 5. Alternatives showed no developmental trend and, as a single category, were variable both within and among the four children.

Linguistic Contingency. The sources of semantic contingency were examined in the relationship between adult utterances and succeeding child utterances that were expansions, alternatives, or expatiations. The major distinction observed was between (1) semantic contingency based on situational context only (contextually related utterances), and (2) semantic contingency based on formal criteria as well as possible situational context (linguistically related utterances). Linguistically contingent child speech used the clause structure of the preceding adult utterance and may or may not have been contextually related; contextually contingent speech did not use the clause structure of the preceding utterance. The agreement of two independent observers with the original judgment made by the investigators of the following categories of linguistic and contextual contingency was .98 and .95 at Stage 1; 1.0 and .95 at Stage 2; and .96 and .96 at Stage 5 .

Linguistic contingency consisted of a semantic relation with structural continuities between the child utterance and the clause structure of the preceding adult utterance. The structural continuities were either intraclausal or interclausal in relation to prior utterances. Intraclausal relations were certain expansions and alternatives in which information was added by the child within the same clause structure and preserved the same verb relation as in the adult utterance. Intraclausal expansions consisted of the addition of a major subject, verb, or object (SVO) constituent that was missing from the adult utterance, a wh-replacement, or the modification of an SVO constituent in the adult utterance, for example:

(7) G (Stage 1)

Mommy sit.

Mommy stool. (addition of SVO constituent)

(8) P (Stage 1)

What's in your hand?

book. (wh-replacement)

(9) K (Stage 2)

Let's take the shoes out.

doll shoes. (modification within SVO)

Intraclausal iterative expansions preserved the same verb relation as the adult utterance, except that the referent of a major constituent such as agent, object, or place was changed. In the situations in which iterative expansions occurred, the adult's utterance referred to some event that was taking place, and the child's utterance referred to an event that was additional, in that it did not oppose the event referred to by the adult but simply went along with it.

(10) K (Stage 2)

(pushing doll on slide)

She climbs up and then she slides down. Kathryn slides too.

(11) K (Stage I)

(Mother washing Kathryn's shoulder and arm in the bath tub)

Wash the shoulder.

(Mother washing her hand) wash hand.

(12) K (Stage I)

(looking at a book)

What are the children doing? Are they stretching?

(Kathryn stretches)

baby stretch.

Interclausal expansions added a verb relation to the verb relation in the adult utterance with another clause that was grammatically subordinate to the clause of the adult utterance and added new information, for example: 
(13) K (Stage 5)

Does my finger fit? no.

Why?

because it's too big.

(14) E (Stage 5)

Yes. Pussy cat is calling to wolf. Why?

because he's up in this building too tall.

(15) K (Stage 5)

Well I think the bear and the doggie would

like to visit the donkey.

but he not gonna have a birthday.

Interclausal expatiations added information to the prior utterance and introduced another related topic, for example:

(16) K (Stage 5)

I can't open it. (lockbox)

yes you can open that one

but I'm gonna lock it so you can't get in.

(17) G (Stage 5)

How did they get there? (berries on trees)

they just picked them up and put them on the hooks on the berries and they hang up them.

Two kinds of alternatives to a prior adult utterance were linguistically contingent. Intraclausal alternatives opposed the idea represented in the adult's utterance while preserving the same verb relation, for example:

(18) P (Stage 1)

You gonna make a house again? (playing with blocks) tunnel.

(19) K (Stage 1)

Don't lock it. (Lois and Kathryn playing with lock box) I'm gonna lock it.

(20) G (Stage 2)

Shall we sit on the sofa and read my book?

(Gia going to orange chair)

orange chair ə read a book.

Choice alternatives presented a choice by the child from more than one alternative presented in the adult utterance, for example:

(21) K (Stage 5)

Did you call her a nurse? Or a stewardess?

a stewardess.

Contextual Contingency. For other contingent discourse, the child's utterance followed from the situation or action in the speech event that included the adult-child interaction. Contextually contingent speech did not use the clause structure of the preceding adult utterance. The child either expanded on or presented an alternative to the idea in the adult utterance with a different verb relation that was not grammatically subordinate to that in the adult utterance.

Contextual expansions added a different verb relation that was contextually related to what the adult said. The most common expansions of this type referred to successive aspects of the situation, for example:

(22) G (Stage 1)

Give it to Lois. (Lois is putting her toys away in her bag) away.

(23) P (Stage 1)

I'll put my scarf on first.

(Getting ready to leave)

home? 
(24) P (Stage 2)

I can't get the bolt off.

need a screw driver?

(25) K (Stage 2)

Where's the other sock?

see my sitting on it.

Contextual alternatives opposed the idea represented in the adult utterance, with a new verb relation, for example:

(26) P (Stage 1)

(Peter trying to open box)

Why don't you put the box back in the bag?

open.

(27) P (Stage 1)

(Peter trying to push buttons on recorder)

I think we're gonna leave the tape recorder alone. push.

(28) E (Stage 5)

Well here's the conductor.

He's sitting up here on the engine. No! Let me take the engine.

(29) G (Stage 5)

We don’t wanna wake him. (Gia's baby brother) I want go see him.

Development of Linguistic and Contextual Contingency

The distribution of the different kinds of linguistic and contextual contingency is presented in Table 3 as proportions of topic-related speech (contingency and imitation). Contextual contingency decreased from Stage 1 to Stage 5 . Within linguistic contingency, intraclausal relations increased, and interclausal relations were a late development at Stage 5. The children were similar to one another, and Figure 4 presents the data combined for the four children. Linguistic contingency developed as the children progressed from imitating to learning to use the information in prior adult messages. They (1) expanded the same verb relation with a Wh-replacement, added constituents or modified constituents within a clause, and, later, (2) added a second verb relation that was grammatically subordinate to the verb relation in the adult utterance. 
Table 3. Proportion of Utterances in Categories of Linguistic and Contextual Contingency

\begin{tabular}{|c|c|c|c|c|c|c|c|c|c|c|c|c|}
\hline \multicolumn{10}{|c|}{ LINGUISTIC CONTINGENCY } & \multicolumn{3}{|c|}{ CONTEXTUAL CONTINGENCY } \\
\hline \multicolumn{6}{|c|}{ Intraclausal Relations } & \multicolumn{4}{|c|}{ Interclausal Relations } & \multirow[b]{2}{*}{ Expansion } & \multirow{2}{*}{\multicolumn{2}{|c|}{$\begin{array}{c}\text { TOTAL } \\
\text { Contextual } \\
\text { Alternative Contingency }\end{array}$}} \\
\hline $\begin{array}{l}\text { Child, } \\
\text { Stage }\end{array}$ & Expansion & $\begin{array}{l}\text { Iterative } \\
\text { Expansion }\end{array}$ & Alternative & Choice & Total & Expansion & Expatiation & & $\begin{array}{c}\text { TOTAL } \\
\text { Linguistic } \\
\text { Contingency }\end{array}$ & & & \\
\hline \multicolumn{13}{|l|}{ Eric } \\
\hline 1 & .25 & .01 & .03 & - & .29 & .01 & - & .01 & .30 & .11 & .01 & .12 \\
\hline 2 & .35 & .03 & .07 & - & .45 & - & - & - & .45 & .18 & .05 & .23 \\
\hline 5 & .35 & .03 & .02 & .01 & .41 & .12 & - & .12 & .53 & .06 & .02 & .08 \\
\hline \multicolumn{13}{|l|}{ Gia } \\
\hline I & .29 & .01 & - & - & .30 & - & - & - & .30 & .16 & .01 & .17 \\
\hline 2 & .25 & .01 & .11 & - & .37 & - & - & - & .37 & .10 & .02 & .12 \\
\hline 5 & .36 & .01 & .11 & .01 & .49 & .06 & .03 & .09 & .58 & .08 & .01 & .09 \\
\hline \multicolumn{13}{|c|}{ Kathryn } \\
\hline 1 & .16 & .01 & .02 & - & .19 & - & - & - & .19 & .14 & .01 & .15 \\
\hline 2 & .19 & .05 & .04 & - & .28 & - & - & - & .28 & .19 & .02 & .21 \\
\hline 5 & .28 & .05 & .07 & .01 & .41 & .17 & .05 & .22 & .46 & .04 & .01 & .05 \\
\hline \multicolumn{13}{|l|}{ Peter } \\
\hline 1 & .08 & - & .02 & - & .10 & - & - & - & .10 & .08 & .08 & .16 \\
\hline 2 & .16 & - & .05 & - & .21 & - & - & - & .21 & .06 & .02 & .08 \\
\hline 5 & .26 & - & .03 & .01 & .30 & .07 & .02 & .09 & .43 & .11 & .02 & .13 \\
\hline
\end{tabular}

${ }^{a} n=$ number of contingent and imitative utterances, at each stage for each child, as in Table 2. Rows sum to total proportions in Subcategories of Linguistic and Contextual Contingency 


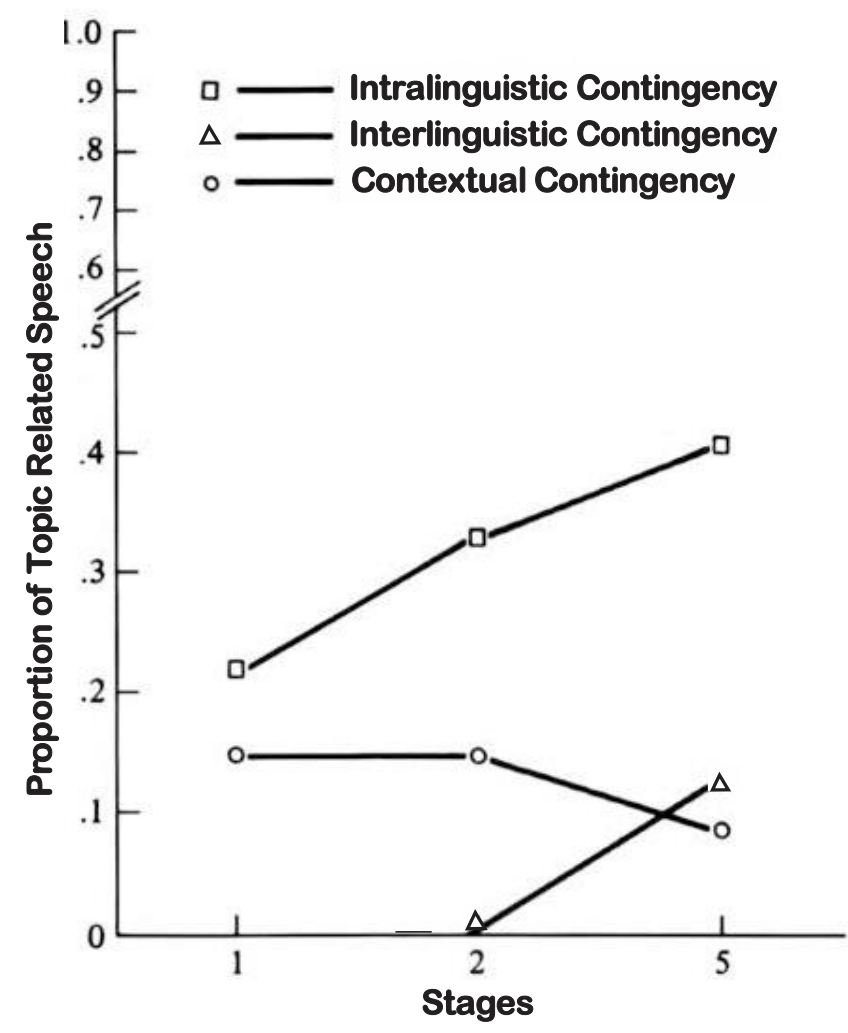

Figure 4. Proportional distribution of topic-related child utterances in categories of contingent speech for the four children combined.

When only contingent speech was examined and imitation was discounted, the proportion of linguistic contingency was the same at Stage 1 and Stage 2 (.39) and increased only from Stage 2 to Stage 5 (.58). This increase in linguistically contingent speech was a function of the appearance of interclausal contingency at Stage 5 , because the proportion of intraclausal contingency was similar at all three stages. Although the proportion of contingent speech that was intraclausal linguistic contingency was the same at Stages 1, 2, and 5, development occurred in the form of linguistic contingency.

\section{Developmental Changes in the Form of Linguistic Contingency}

Several kinds of lexical and structural continuity between adjacent adult and child messages shared the same topic. The distribution of the forms of linguistic contingency was similar in the speech of the four children, and this result is presented in Figure 5 for the data from the four children combined.

Most frequently and overwhelmingly at Stage 1, the child utterance consisted of a word or a phrase that was either an additional constituent or replaced a constituent in the adult utterance, for example.

(30) K (Stage 1)

Put this on with a pin.

sharp.

(31) P (Stage 1)

You gonna make a house again?

tunnel. 


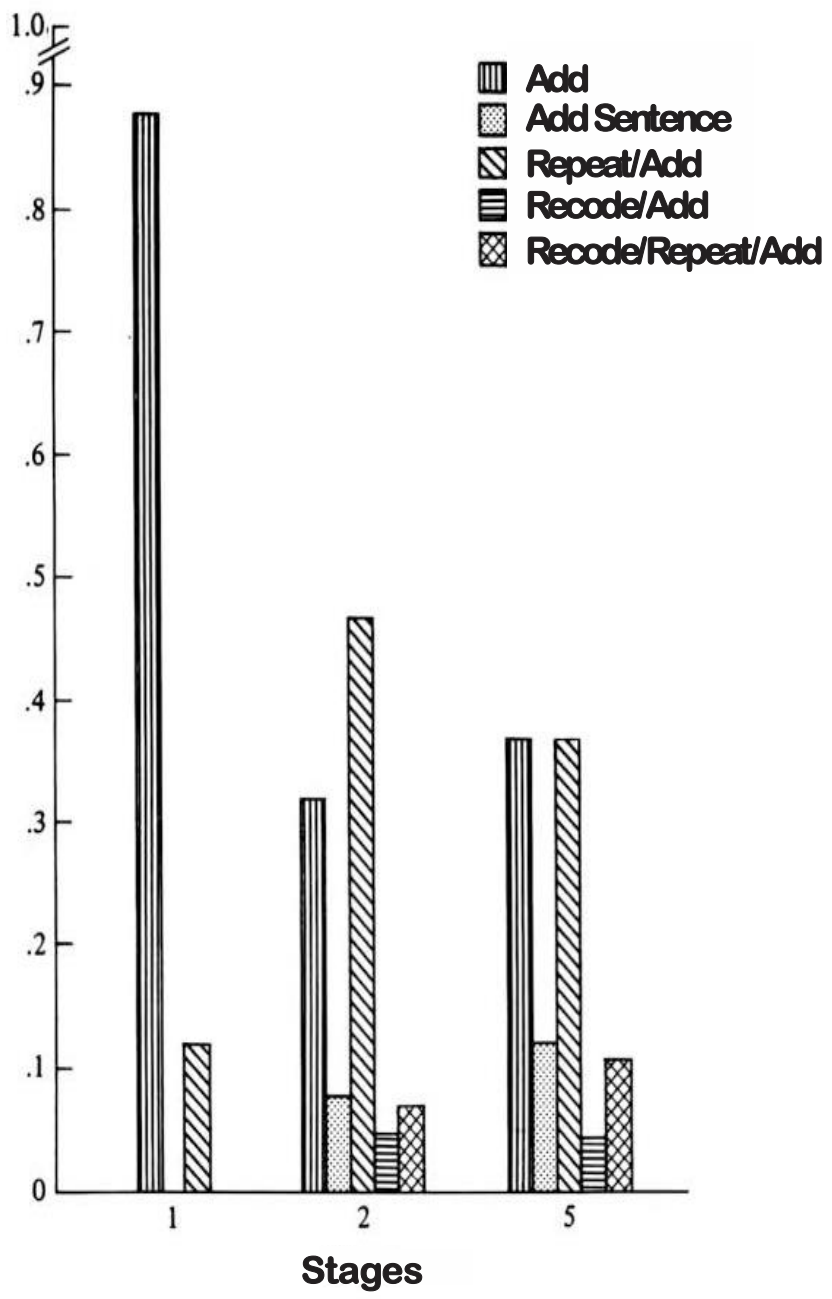

Figure 5. Proportional distribution of the forms of linguistic contingency for the four children combined.

Beginning at Stage 2 and continuing in Stage 5, the child utterance could represent an added sentence, for example:

(32) K (Stage 5)

Well, where's Gary?

he doesn't come to the party.

(33) P (Stage 5)

Where did you get that?

when Santa Claus came he bring me my bed and of course and vacuum cleaner.

At Stage 2, the predominant form of linguistic contingency consisted of a repetition of part of the adult utterance with the addition or replacement of a lexical item or a phrase in the adult utterance (Repeat/ Add in Figure 5), for example:

(34) P (Stage 2)

What did I draw?

draw a boy.

(35) G (Stage 2)

Can I read it?

I wanna read it. 
(36) E (Stage 2)

I didn't bring the choo-choo train today. $\quad$ o bring a choo-choo train tomorrow?

The most frequently repeated constituent at both Stage 2 and Stage 5 was the verb. For all children combined, .66 of all the Repeat/Add utterances at Stage 2 and .55 at Stage 5 contained the verb as one of the repeated constituents.

Beginning at Stage 2 and continuing in Stage 5, the child utterance could both recode the adult utterance and add to it, or recode and repeat part of the adult utterance while also adding to it (Recode/Add and Recode/Repeat/Add in Figure 5), for example:

(37) P (Stage 2)

You do that one.

now I do that one.

(38) P (Stage 2)

What are you going to do?

(Peter setting up doll house)

I'm gonna make something in this.

(39) (Stage 5)

Where did you get it? (Christmas tree) I got it from the Christmas tree man.

Asking Contingent Questions

Children's Questions. The children's linguistically contingent speech included wh-questions at Stage 5, but not at Stages 1 and 2, and it appears that the development of linguistically contingent questions did not begin until sometime between Stages 2 and 5. Of the children's noncontingent speech, .11 utterances were questions at Stage 2, and .16 were questions at Stage 5, in comparison with linguistically contingent speech in which there were no questions at Stage 2 and .13 questions at Stage 5. Using the information in a prior utterance to ask a $w h$-question, that is, asking a question that is linguistically contingent, appears to have been more difficult than producing a linguistically contingent statement or asking a noncontingent question. While $w h$-questions occurred in the children's speech at Stage 2, they were not linguistically contingent until after Stage 2.

Adults' Questions. The effect of adults' use of questions and nonquestions on the children's development of discourse was examined. All $w h$-questions and yes-no questions from the adults were counted as questions, except those that functioned as requests (e.g., "Why don't you sit over here?” or “Will you bring it over?”), which were counted as nonquestions. For this analysis the CS was expanded to include all intervening adult utterances to which the children did not respond. The original CS, then, consisted of child speech that was adjacent and nonadjacent to adult speech; the expanded CS included the CS plus all other adult utterances within the same sample. The proportion of adult questions increased from .38, Stage 1, to .49, Stage 2, and .60, Stage 5. At all three stages (Table 4), (1) linguistic contingency, which increased, occurred more often after adult questions than after nonquestions; (2) imitation and no response, both of which decreased, occurred more often after nonquestions than after questions; (3) contextual contingency tended to occur more often after nonquestions.

Because linguistic contingency occurred more often after adult questions than nonquestions and the proportion of adult questions increased, one might hypothesize that the developmental increase in linguistic contingency occurred because the adults tended to ask more questions at Stage 2 and then again at Stage 5 . This was clearly not the case; the number of adult questions in the expanded CS actually decreased for Eric, Kathryn, and Peter from 564, Stage 1, to 448, Stage 5 (see Table 4). Even though there were actually fewer opportunities for linguistic contingency to occur after questions for three of the children, the number of linguistically contingent utterances increased from 90 to 289. (The number of adult questions did increase for Gia, from 128 at Stage 1 to 228 at Stage 5, but the increase in linguistic contingency for Gia, from 51 to 119, was smaller than for the other children.) 7

7 The results presented in Table 4 showing that the number of adult utterances decreased may appear to contradict the results presented in Figure 2, which indicates an increase in adult speech frequency. However, the absolute number of adult utterances spoken in the span of 400 child utterances is presented in Table 4, whereas Figure 12 represents the 
Table 4. Child Discourse Categories After Questions and Nonquestions in Adult Speech

\begin{tabular}{|c|c|c|c|c|c|c|c|}
\hline \multirow[b]{2}{*}{$\begin{array}{l}\text { Child, } \\
\text { Stage }\end{array}$} & \multirow[b]{2}{*}{$\begin{array}{l}\text { Adult Speech } \\
\text { p (n) }\end{array}$} & \multicolumn{6}{|c|}{ Proportion and Frequency of Child Speech After Questions and Nonquestions } \\
\hline & & $\begin{array}{c}\text { Linguistic } \\
\text { Contingency }\end{array}$ & $\begin{array}{c}\text { Contextual } \\
\text { Contingency }\end{array}$ & Imitation & Noncontingent & No Response & Other $^{\mathrm{a}}$ \\
\hline \multicolumn{8}{|l|}{ Eric } \\
\hline \multirow[t]{2}{*}{1} & $+Q \cdot 51(281)$ & $.13(37)$ & $.04(11)$ & $.05(15)$ & $.22(61)$ & $.47(133)$ & $.09(24)$ \\
\hline & $-Q .49(273$ & $.03(9)$ & $.04(10)$ & $.12(34)$ & $.22(61)$ & $.51(138)$ & $.08(21)$ \\
\hline \multirow[t]{2}{*}{2} & $+Q \cdot 54(183)$ & $.22(41)$ & $.09(16)$ & $.02(4)$ & $.27(50)$ & $.30(54)$ & $.10(18)$ \\
\hline & $-Q .46(155)$ & $.12(18)$ & $.08(12)$ & $.10(15)$ & $.26(41)$ & $.38(59)$ & $.06(10)$ \\
\hline \multirow[t]{2}{*}{5} & $+Q .60(190)$ & $.48(92)$ & $.04(7)$ & $.01(1)$ & $.18(34)$ & $.03(6)$ & $.26(50)$ \\
\hline & $-Q .40(129)$ & $.19(24)$ & $.08(10)$ & $.12(16)$ & $.29(38)$ & $.16(21)$ & $.16(20)$ \\
\hline \multicolumn{8}{|l|}{ Gia } \\
\hline \multirow[t]{2}{*}{1} & $+Q \cdot 32(128)$ & $.29(37)$ & $.04(5)$ & $.09(12)$ & $.19(24)$ & $.30(38)$ & $.08(10)$ \\
\hline & -Q .68 (275) & $.05(14)$ & $.08(23)$ & $.21(58)$ & $.27(74)$ & $.36(98)$ & $.03(8)$ \\
\hline \multirow[t]{2}{*}{2} & $+Q .56(204)$ & $.27(56)$ & $.04(8)$ & $.01(2)$ & .09 (19) & $.20(40)$ & $.39(79)$ \\
\hline & $-Q .44(160)$ & $.09(14)$ & $.09(14)$ & $.01(1)$ & $.09(15)$ & $.66(105)$ & $.07(11)$ \\
\hline \multirow[t]{2}{*}{5} & $+Q .67(228)$ & $.40(91)$ & $.03(7)$ & $-(1)$ & $.22(50)$ & $.09(20)$ & $.26(59)$ \\
\hline & $-Q \cdot 33(114)$ & $.25(28)$ & $.10(11)$ & $.01(1)$ & $.43(49)$ & $.12(14)$ & $.10(11)$ \\
\hline \multicolumn{8}{|c|}{ Kathryn } \\
\hline \multirow[t]{2}{*}{1} & $+Q \cdot 38(172)$ & $.12(21)$ & $.06(10)$ & $.17(30)$ & $.24(42)$ & $.29(50)$ & $.11(19)$ \\
\hline & $-Q .62(278)$ & $.04(12)$ & $.06(17)$ & $.22(61)$ & $.28(79)$ & $.35(98)$ & $.04(11)$ \\
\hline \multirow[t]{2}{*}{2} & $+Q \cdot 39(124)$ & $.23(29)$ & $.07(9)$ & $.08(10)$ & $.23(29)$ & $.06(8)$ & $.31(39)$ \\
\hline & -Q .61 (192) & $.09(18)$ & $.13(25)$ & $.14(26)$ & $.38(72)$ & $.21(40)$ & $.06(11)$ \\
\hline \multirow[t]{2}{*}{5} & $+Q .54(138)$ & $.49(68)$ & $.05(7)$ & $.03(4)$ & $.14(20)$ & $.06(8)$ & $.22(31)$ \\
\hline & $-Q .46(116)$ & $.31(36)$ & $.01(1)$ & $.01(1)$ & $.24(28)$ & $.29(34)$ & $.14(16)$ \\
\hline \multicolumn{8}{|l|}{ Peter } \\
\hline \multirow[t]{2}{*}{1} & $+Q .29(111)$ & $.06(7)$ & $.04(4)$ & $.17(19)$ & $.50(56)$ & $.22(24)$ & $.01(1)$ \\
\hline & $-Q .71(268)$ & $.01(4)$ & $.05(14)$ & $.20(54)$ & $.40(107)$ & $.29(79)$ & $.04(10)$ \\
\hline \multirow[t]{2}{*}{2} & $+Q .45(144)$ & $.13(19)$ & $.03(5)$ & $.08(11)$ & $.25(36)$ & $.23(33)$ & $.28(40)$ \\
\hline & $-Q \cdot 55(179)$ & $.05(9)$ & $.02(4)$ & $.13(23)$ & $.34(60)$ & $.36(64)$ & $.11(19)$ \\
\hline \multirow[t]{2}{*}{5} & $+Q \cdot 55(120)$ & $.43(52)$ & $.08(10)$ & $.02(2)$ & $.13(16)$ & $.04(5)$ & $.29(35)$ \\
\hline & $-Q .45(100)$ & $.17(17)$ & $.11(11)$ & $.08(8)$ & $.18(18)$ & $.07(7)$ & $.39(39)$ \\
\hline
\end{tabular}

aOther $=$ yes/no, social routine, recoding, self-expansion, self-recoding.

average number of utterances per hour. Because the relative increase in adult speech frequency was less than the relative increase in child speech frequency (Figure 2), it follows that the absolute number of adult utterances spoken in the span of 400 child utterances would decrease as the time span decreased. 
The distribution of the major discourse categories (imitation, linguistic contingency, contextual contingency, etc.) in response to adult questions and nonquestions is presented in Table 4. As can be seen, linguistic contingency was more frequent after questions and increased for both questions and nonquestions. However, the proportional increase was greater for nonquestions than for questions. For example, for Kathryn the change in linguistic contingency in response to questions from Stage 1 to Stage 5 was .12 to .49, which represents a fourfold increase, while in response to nonquestions, there were proportionately eight times more linguistically contingent responses (.04 to .31). Thus, although linguistic contingency was always more frequent after questions than nonquestions, with development the children began to give relatively more linguistically contingent speech in response to nonquestions.

This tendency for responses to become distributed more evenly between questions and nonquestions from Stage 1 to Stage 5 held for the other discourse categories in addition to linguistic contingency. At the same time, however, there was a concomitant trend in the speech of the adults; the proportion of adult utterances that were questions increased from Stage 1 to Stage 5. These two developmental trends acted as competing factors, producing the result shown in Figure 6, where the proportion of each of the major child discourse categories that occurred after adult questions is shown for the four children combined. As can be seen, the proportion within each category (imitation, linguistic contingency, contextual contingency, and no response) that occurred after questions was essentially the same at each stage. This constancy in the proportion of the various discourse categories in response to adult questions was a direct result of the competing effects from the proportional increase in adult questions and the proportional increase in child responses to nonquestions. As a consequence, there was an equilibrium maintained between adult and child in their discourse interaction. ${ }^{8}$

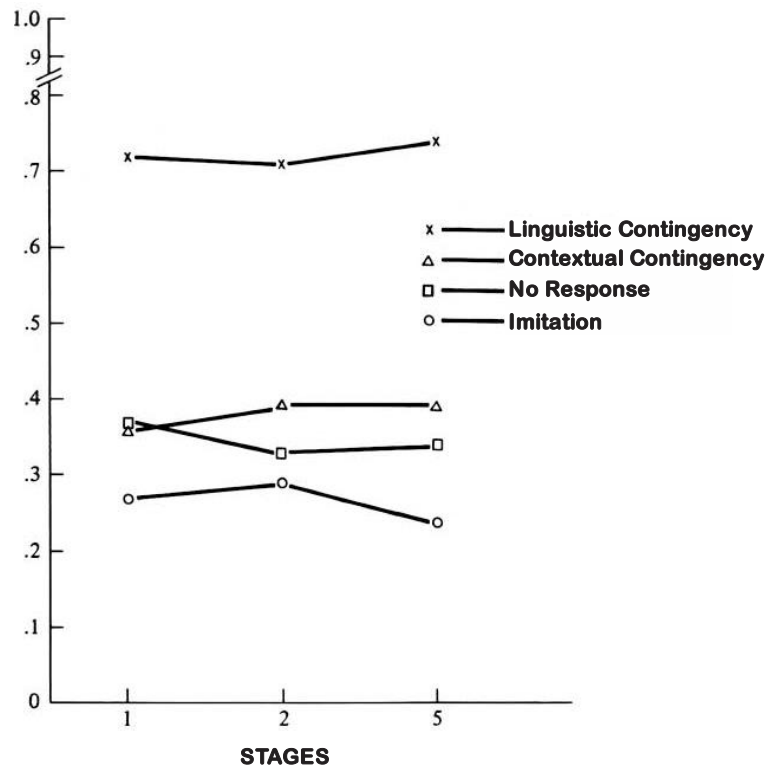

Figure 6. Proportion of child discourse categories in response to adult questions for the four children.

8 The results presented in Figure 6 are predictable given the conditional probabilities of each of the discourse categories occurring in response to questions and nonquestions. To illustrate, the following formula predicts the result shown in Figure 6 for linguistic contingency:

$$
p(q / c)=p(q) \cdot p(\mathrm{c} / q) / p(q) \cdot p(c / q)+[\mathrm{I}-p(q) \cdot p(c / n q)
$$

where $p(q / c)=$ the probability that a question preceded a linguistically contingent utterance (i.e., the data in Figure 6); $p(c / n q)=$ the probability that a nonquestion preceded a linguistically contingent utterance; and $p(q)=$ the probability that an adult utterance is a question (i.e., the data in Table 4). The observed rise in $p(q)$ (from .38 at Stage 1 to .60 at Stage 5), which with age would lead to an increase in $p(q / c)$, and the observed rise in $p(c / n q)$, which with age would lead to a decrease in $p(q / c)$, counteracted each other, leading to the result presented in Figure 6. 


\section{Discourse Support from the Child for Linguistic Contingency}

The results presented thus far have been based on adjacent adult-child utterance pairs, and one question that remains is how often the adult- child contingency relations actually originated with a preceding utterance from the child, as in the following example:

(40) G (Stage 2)

(pointing to space for tank on tank car)

uh oh missing.

Uh oh what's missing?

missing tank car.

Gia's second utterance is linguistically contingent on the adult utterance, and both are linguistically contingent on the preceding child utterance.

Less than .20 of the children's linguistically related utterances were also linguistically contingent on a preceding child utterance (.15 at Stage 1, .16 at Stage 2, and .19 at Stage 5). More often, then, the children's speech was linguistically contingent when the topic originated with the adult utterance than with a prior child utterance. When the topic originated with a prior child utterance, the intervening adult utterance functioned as a 'prompt' in the form of an imitation or asked for an expansion from the child. Most often, the adult either (1) imitated part or all of the first child utterance and the second child utterance was really a self-expansion or (2) asked a $w h$-question based on the first child utterance and the child responded to the $w h$-question. Imitative adult utterances were most frequent at Stage 1 and decreased to Stage 5; and adult $w h$-questions were least frequent at Stage 1 and increased to Stage 5 .

\section{DISCUSSION}

Fillmore (1971/1973) has compared the interaction in discourse to a "game of catch" played by throwing balls into the air. Each player comes to the game with a basket of balls and knowledge of the basic rule that only one ball can be in the air at any one time-thus distinguishing the game of catch from other games with balls such as warfare or juggling. Tossing a ball into the air corresponds to contributing something to a conversation, and Fillmore described different versions of the game that are analogous to different kinds of conversation between speakers.

In the first version of the game, one player begins by picking up a ball and throwing it in the air. Another player watches the ball, catches it, and throws it back to the first player, who, in turn, watches the ball, goes to where it will land, catches it, and throws it again to the second player. The ball represents the topic of the conversation and goes back and forth in this way, until either of the players lets the ball fall to the ground or else the first player puts it back in the basket.

In the second version of the conversation game described by Fillmore, one player takes a ball and throws it into the air. The other player waits until it falls to the ground and then picks up another ball and throws it into the air. The other players wait for it to land, and then the first player or someone else throws a ball into the air again. Although the players are taking turns, they are not sharing a topic of conversation.

Fillmore's conversation metaphor is relevant to the major results of this study of adult-child discourse in the following ways: More of the children's utterances were adjacent to an utterance from someone else than they were nonadjacent-that is, they occurred in a context in which someone else had just said something. Already at Stage 1, then, the children had learned the first basic rules of discourse: (1) only one ball can be in the air at one time, and (2) you throw your ball in the air after someone else throws theirs. Recent research by Stem, Jaffe, Beebe, and Bennett (1975) would indicate that these early rules of discourse are developmental and learned sometime after the first few months of life. They reported that the largest proportion of the vocalization of the infants they observed was "co-actional" at 3 to 4 months, as children vocalized more often in unison with their mothers than in a "dialogic" or alternating pattern.

However, child utterances were largely noncontingent at Stages 1 and 2, so that although the children knew that talking was reciprocal and they were taking conversational turns, they were playing the second conversation game described by Fillmore about half the time: One player throws a ball in the air, the other player waits for it to fall 
to the ground and then throws another ball into the air ... and so on. By the time the children were 3 years old, at Stage 5, they were playing the first version of the conversation game fairly well: The same ball (representing the topic of conversation) went back and forth between speakers, and the children added new information to the topic most of the time.

There were two possible explanations of the children's speech that was either nonadjacent or adjacent but noncontingent: first, that such speech functioned to change the topic of conversation or introduce a topic and, second, an explanation that is not mutually exclusive with the first, that it is easier for children to produce spontaneous speech than to produce contingent speech. The children introduced new topics or changed the topic of conversation with more than half of what they said at Stage 1. By Stage 2, nonadjacent speech had increased in the same proportion that noncontingent speech decreased (Figure 3), and for two of the children nonadjacent speech had increased again by Stage 5 . Thus, the children were becoming more active in initiating conversational exchanges-no doubt as a result of how adults were responding to them (which was explored in the present study only to a limited extent).

However, even though the children might have chosen to change the topic of conversation, there is also evidence to indicate that it may be more difficult to produce a contingent message than to produce a 'spontaneous' message. First, it was apparently more difficult for the children in this study to ask a wh-question in response to a prior utterance from someone else than to ask a wh-question spontaneously at Stage 2. At Stage 2, .11 of the children's noncontingent speech were questions, which is consistent with other reports of the frequency of questions in children's speech: .13 of the speech from children in the age range 18 to 72 months studied by Smith (1933) and .14 from children in the age range 36 to 54 months studied by McCarthy (1930). However, questions did not appear in the children's contingent speech until Stage 5. Second, in studies of the development of negation in child language, both McNeill and McNeill (1968) and Bloom (1970) observed that negative sentences that express denial of the truth of a prior statement, for example, "That's not truck" (after "Here's a truck"), develop after negative sentences with other semantic functions, such as nonexistence and rejection of objects and events. In a study by Belkin (1975), expressions of denial occurred more frequently and developmentally earlier after questions than after statements-which is consistent with the results for linguistic contingency reported here.

In addition, the difference between spontaneous and elicited speech provides further evidence of the different processes involved in producing spontaneous and contingent messages, as is evident in the following example from Bloom (1974). ${ }^{9}$ Although Peter imitated often in naturalistic situations and he willingly played 'the game' when asked to imitate sentences, he was unable to reproduce the same sentences that he had said spontaneously on the preceding day. For example, when asked to repeat, "I'm trying to get this cow in there," Peter said, "Cow in here," and when asked to repeat, "You made him stand up over there," Peter said, "Stand up there." It appears, then, that Peter's spontaneous speaking ability, given the support of contextual events and his own intention, exceeded his ability to say sentences that he was asked to imitate without such support, even though they were the very same sentences that he himself had produced at another time (see also Maratsos \& Kuczaj, 1975; Slobin \& Welsh, 1973).

While increase in linguistic contingency was a major development in discourse in the present study, it still accounted for less than half the adjacent speech the children produced when they were 3 years old. This result and the above observations have implications for the evaluation that is given to children's language performance when assessing their language development. Children's linguistic behavior is often assessed in situations in which speech is elicited from the child-as in experimental tasks that involve question answering and elicited imitation. Such tasks present children with a situation in which they are expected to produce a contingent response, which is fundamentally different from producing a message that expresses their own semantic intention (see Figure 7).

Three cognitive components interact with one another and with information from linguistic and nonlinguistic events in the child's context, as the child either produces or understands messages. There is (1) the child's memory-the conceptual information about objects and events in the world; (2) the child's scheme for linguistic processing for both decoding linguistic forms, in order to obtain information or meaning, and using linguistic

9 From data collected in collaboration with Patsy Lightbown. 
forms, in order to represent information in messages to other persons; and (3) the child's immediate consciousness-what the child thinks about when producing an utterance or hearing an utterance from someone else. The three components and the interactions that underlie different states of affairs for speaking and understanding in language development are schematized in Figure 7.

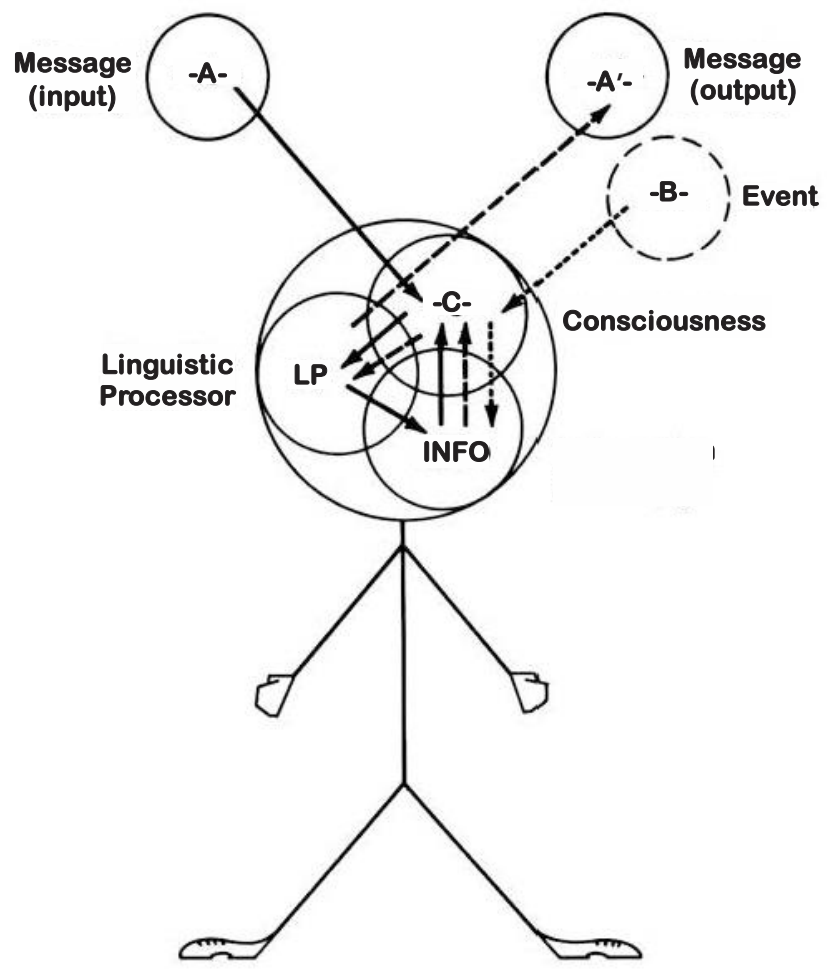

Figure 7. A model for understanding and producing information in messages.

The two situations in which the child either hears a message (A) that maps onto a contextual event (B) or produces a message (A') relative to a contextual event (B) are the two situations which predominate in early child language-when children both understand and speak in the 'here and now.' However, from the beginning of child language and with increasing frequency through to adulthood, messages are understood and messages are produced without the necessary support of an encoded event in the context (B) being perceptually available to the child's consciousness (C). When the child hears a message (A) and the only information about the meaning of the message in (A) is available to the child through processing the linguistic signal in relation to information about the world in memory, the task is to create a mental representation of the meaning of the message in consciousness (C). In turn, that represented meaning of the prior message can then be related to some new content in memory to form the basis for a contingent semantic intention-the situation schematized in Figure 7, in which the child's message (A') depends upon processing information from input (A, indicated by the solid lines) as a condition for processing information for output ( $\mathrm{A}^{\prime}$, indicated by the dashed lines). This capacity is the goal of language development and is the capacity upon which the development of discourse would appear to depend, where the topic of conversation is shared by different speakers. In the present study, observations were made of the formal and semantic relations between contingent child utterances ( $\mathrm{A}^{\prime}$ ), and prior adult utterances (A), while the extent to which there were corresponding events in the context, possible (B), was not explored directly.

If one considers that the categories of nonadjacent and adjacent speech reported here were exhaustive, that is, all of the CS from each child at each stage was accounted for, then, to the extent that the CS was representative of the children's discourse, the following conclusions appear to follow: First, it seems that certain rules of 
discourse could function independently of the cognitive processes involved in speaking and understanding. The children knew to say something after another person had spoken. Utterances that did not share the topic of prior messages occurred when the children's knowledge of this basic rule of discourse operated without their necessarily processing the prior message, as they attended to something else or changed the topic. Such messages that introduced a new topic are represented in Figure 7 with the dashed lines that indicate how the child would raise some information from memory (with or without an association with some event in the context) to consciousness, forming a semantic intention to express in an output utterance.

In the more complex situations in which the topic of a prior utterance was shared, the children very often shared the topic by saying the same thing - that is, they imitated. This result complements the results of a previous study of imitation in which the function of imitation for lexical and grammatical learning was investigated (Bloom, Hood, \& Lightbown, 1974). ${ }^{10}$ Imitation was, therefore, one of the earliest strategies available for discourse, as observed also by Keenan (1974a). Considering the cognitive processes for speaking diagrammed in Figure 7, it would appear that the easiest way to process the relation between linguistic form and nonlinguistic content in a prior utterance (and maintain the topic of conversation at the same time) would be to either imitate, without needing to recall new forms or content from memory, or add a new form that complemented the form and content of the prior utterance - given some representation of the prior utterance in (C). At Stage 1, the children either imitated or added to adult utterances but did not both repeat and add in the same utterance as they did in Stage 2 (Figure 5). Moreover, at Stage 1, imitation occurred most often after statements, and adding (linguistic contingency) occurred most often after questions - which indicated that the children discriminated between questions and statements in adult speech and responded differently to each.

The major development in the children's discourse from Stage 1 to Stage 5 was the increase in messages that shared the topic of a prior utterance with added information. This increase in contingency was characterized primarily by expansions, in which the verb of the prior utterance was repeated and something was added to it: Either major sentence constituents were added or modified, or a $w h$-form was replaced by a word or a phrase. The explanation of this result that is most consistent with the reported function of imitation for language learning at Stage 1 (Bloom, Hood, \& Lightbown, 1974) is that children were learning the lexical and grammatical functions of verbs. However, the children were also learning a major device for texting in conversation (Halliday \& Hasan, 1976), as the developing discourse between speakers shared the same constituents (see Harris, 1964). While the evidence available so far does not differentiate between these two possible explanations, it seems safe to conclude that discourse develops between adult and child as a function of learning both language use and the relations between language form and content (lexicon and grammar). Social interaction, then, may be complementary rather than primary. Children learn language form and content through discourse as they learn how to participate in conversations.

One important aspect of this study has not been made explicit as yet. There were changes in the children's speech, and there were also changes in the adults' speech as well. The adults asked proportionately more questions as children's linguistically contingent responses to questions increased. In their own responses to the children, the adults tended to repeat what the child said less frequently and to ask wh-questions for expansions more frequently-as the children also were imitating less and expanding more in the time from Stage I to Stage 5. The patterns in the development of discourse that have been described no doubt resulted from mutual influences between adult and child, and the feedback that each receives in the course of their interaction. Children pay attention to those aspects of the adult speech that they hear which they are in the process of learning or which they need to learn, and adults progressively modify their speech to children in order to provide a model that is responsive to the child's evolving needs and capacities. An important cue is provided the adult by the kind of response the child gives, and changes in the child's discourse patterns will influence the adults' response patterns. Thus, there were changes in the children's speech that depended presumably upon factors of age and ability, as well as upon complementary changes on the part of the adults in conversation (see also the studies of

10 In the earlier study of imitation, the children differed in frequency of imitation, with imitation counted for utterance types rather than utterance tokens (as in the present study). The type-token ratios for imitation in the CS at Stage 1 were Kathryn, .91; Peter, .85; Eric, .70; and Gia, .57. Gia, who imitated types least often, had more imitated tokens than did Kathryn and Peter, who imitated types most often. Thus the results of the two studies are not contradictory. 
mother-child interactions by Moerk, 1975; Nelson, 1973; Phillips, 1973; Seitz \& Stewart, 1975; Soderbergh, 1974; and others).

\section{Other Studies of Child Discourse}

The description of the linguistic exchanges in adult-child dyads can be compared with the results of studies of peer dyads that have been reported by Garvey (1974), Garvey and Hogan (1973), and by Keenan (1974b). Both Keenan (with 29-month-old twins) and Garvey and Hogan (with 3- to 5-year-olds) have emphasized children's use of repetition and routines in peer interactions. In contrast, routines were infrequent in the present study, and imitation per se was an early discourse strategy that virtually disappeared by Stage 5. It would seem then that the development of discourse (at least as defined as the ability to share the same topic and add information to a prior utterance from someone else) depends upon the monitoring by an adult who can provide input in relation to the child's capacities for output. In peer interaction, where such monitored support is presumably not available, children may revert to earlier behaviors for sharing topics in conversation. Moreover, there is some evidence that the topics that are so shared are limited. The exchanges between the 29-month-old twins that Keenan described, in which the children expanded one another's utterances (or both repeated and expanded, Repeat/Add) consisted most often of fragments of songs and nursery rhymes.

Shapiro, Roberts, and Fish (1970) compared the echoing behavior of schizophrenic children (mean age 55 months) and normal children (2 to 4 years of age) and distinguished between exact repetition and "mitigated" or "restructured" echoing (where the children repeated and added, or added to and reduced, a prior utterance). They found that both groups of children produced exact repetitions, but only the nonschizophrenic children also used restructured echoing. Although the schizophrenic children echoed the speech they heard, they did not also produce contingent messages that added information to the topic of conversation. In addition, among the normal children, exact repetition was most frequent among 2-year-olds and restructured echoing was most frequent among the 4-year-olds, which corresponds to the results presented here. Other studies have also reported a higher incidence of imitation among younger children and a decline in imitation with development (for example, Moerk, 1975; Seitz \& Stewart, 1975; Shipley, Smith, \& Gleitman, 1969; Slobin, 1968). However, when a distinction was made between just imitation, and imitation in combining with recoding and adding, as in the present study, imitation did not actually decline so much as it changed with development, as the children learned to both repeat and add in conversation.

\section{Patterns of Adult Discourse}

It is not clear how the adult-child interactions reported here compare with adult discourse, or even if the same categories are applicable. In fact, a preliminary analysis reveals that adult-adult discourse can differ from adult-child discourse in important ways. An attempt was made to apply the discourse categories observed here to transcripts of conversations between adults that have been reported elsewhere: One was the conversations between President Gerald R. Ford and others in his office, published in the New York Times Magazine, April 20, 1975; another was the conversations between a married couple on vacation reported by Soskin (1963).

In the presidential transcripts, over .90 of the reported adjacent messages were contingent, as compared with approximately .70 of the children's utterances at Stage 5 in the present study. The adult discourse generally did not fall into any of the categories of linguistic or contextual contingency that characterized the children's discourse. That is, they neither shared the verb relation of the preceding utterance, nor were their utterances related by events in the nonlinguistic context due to the absence of relevant nonlinguistic events in the immediate context. Rather, utterances were linguistically contingent as a respondent used the information in a prior message and shared the topic of conversation, but did so most often by using another verb relation and, sometimes, by paraphrasing the preceding verb relation and/or elaborating on it with additional verb relations, for example:

1. Theis: Father Hesburgh, who was a leader of the antiwar movement, strongly suggested we avoid Southeast Asia. The subject of hunger...

Ford: I'm not talking about Vietnam or Cambodia (p. 34). 
2. Ford: As long as he could get some input from you and others besides myself ...

Rumsfeld: Sure. He does that all day every day (p. 46).

3. Ford: My wife and I watch the Miss America contest all the time. We really enjoy that on TV.

Miss America: I sure hope you saw it this year (p. 32).

Thus, it seems that the kind of linguistic contingency observed for the children is not the final goal in the development of discourse, and development would continue, particularly as the children learned more verbs.

In contrast, in a portion of the Soskin (1963) transcript, the conversation recorded between a husband and wife while they were rowing in a boat was not so different from the patterns of adult-child discourse that have been described in this study. In particular, there were many of the same kinds of contextual and linguistic expansions. The Soskin transcript was situationally quite different from the President Ford transcript, especially in terms of the personal and status relations between the participants, and the extent to which the context supported the topic of conversation, for example, Southeast Asia and the Miss America contest in contrast with the cabins on the lake and the waves from the oars. Also, it is not clear to what extent the presidential transcripts were edited, and the participants in the Soskin transcripts were noticeably self-conscious about the recording procedure. Thus, no claim can be made here about the extent to which each of these transcripts is representative of adult discourse. Simply as illustrations, however, they indicate that while the patterns of conversation between adults and children described in the present study are not the final goal in the development of discourse, they are patterns that are available as well to adults in conversation, depending upon such factors in the situation as personal relationship, context, and topic. 


\section{REFERENCES}

Baldwin, A., \& Baldwin, C. (1973). The study of mother-child interaction. American Scientist, 61, 714-21.

Belkin, A. (1975). Investigation of the functions and forms of children's negative utterances. Ph.D. diss., Columbia University.

Bloom, L. (1970). Language development: Form and function in emerging grammars. Cambridge, MA: MIT Press.

Bloom, L. (1974). Talking, understanding and thinking. Developmental relationship between receptive and expressive language. In R. Schiefelbusch \& L. Lloyd (Eds.), Language perspectives - Acquisition, retardation, and intervention (pp. 285-312). Baltimore: University Park Press.

Bloom, L. (1992). Racism in developmental research. President's Message, Division 7 Newsletter. Washington, DC: American Psychological Association, Fall-Winter.

Bloom, L., Hood, L., \& Lightbown, P. (1974). Imitation in language development: If, when and why. Cognitive Psychology, 6, 380-420.

Bloom, L., \& Lahey, M. (1978). Language development and language disorders. New York: Wiley.

Bloom, L., Lightbown, P., \& Hood, L. (1975). Structure and variation in child language. Monographs of the Society for Research in Child Development, 40 (serial no. 160).

Broen, P. (1972). The verbal environment of the language learning child. ASHA Monographs, 17. Washington, D.C.: American Speech and Hearing Association.

Brown, R. (1973). A first language, the early stages. Cambridge, MA: Harvard University Press.

Fillmore, C. (1971, 1973). Deixis, I. Unpublished lectures.

Garvey, C. (1974). Some properties of social play. Merrill-Palmer Quarterly, 20, 163-80.

Garvey, C., \& Hogan, R. (1973). Social speech and social inter-action: Egocentrism revisited. Child Development, $44,562-8$.

Halliday, M., \& Hasan, R. (1976). Cohesion in English. London: Longman Group (English Language Series).

Harris, Z. (1964). Discourse analysis. In J. Fodor \& J. Katz (Eds.), The structure of language (pp. 355-83). Englewood Cliffs, NJ: Prentice-Hall. (Originally published in 1952)

Keenan (Ochs), E. (1974a). Again and again: The pragmatics of imitation in child language. Paper presented to the Annual Meetings of the American Anthropological Association, Mexico City.

Keenan (Ochs), E. (1974b). Conversational competence in children. Journal of Child Language, 1, 163-83.

Maratsos, M., \& Kuczaj, S. (1974). Evidence from elicited imitation for preproductive competence in a grammatical system. Papers and reports on child language development, 7, pp. 65-77). Department of Linguistics, Stanford University.

McCarthy, D. (1930). The language development of the preschool child. Institute of Child Welfare Monograph Series, no. 4. Minneapolis: University of Minnesota Press.

McNeill, D., \& McNeill, N. (1968). What does a child mean when he says "no"? In E. Zale (Ed.), Proceedings of the conference on language and language behavior (pp. 51-62). New York: Appleton-Century-Crofts.

Moerk, E. (1975). Verbal interactions between children and their mothers during the preschool years. Developmental Psychology, 11, 788-94.

Nelson, K. (1973). Structure and strategy in learning to talk. Monographs of the Society for Research in Child Development, 38 (serial no. 149).

New York Times Magazine, April 20, 1975. 
Phillips, J. (1973). Syntax and vocabulary of mothers' speech to young children: Age and sex comparisons. Child Development, 44, 182-5.

Seitz, S., \& Stewart, C. (1975). Imitations and expansions: Some developmental aspects of mother-child communication. Developmental Psychology, 11, 763-68.

Shapiro, T., Roberts, A., \& Fish, B. (1970). Imitation and echoing in young schizophrenic children. Journal of the American Academy of Child Psychiatry, 9, 421-39.

Shipley, E., Smith, C., \& Gleitman, L. (1969). A study in the acquisition of language: Free responses to commands. Language, 45, 322-42.

Siegel, G. (1963). Adult verbal behavior in "play therapy" sessions with retarded children. Journal of Speech and Hearing Disorders (Monograph Supplement no. 10).

Slobin, D. (1968). Imitation and grammatical development in children. In N. Endler, L. Boulter, \& H. Osser (Eds.), Contemporary issues in developmental psychology (pp. 437-43). New York: Holt, Rinehart \& Winston.

Slobin, D., \& Welsh, C. (1973). Elicited imitation as a research tool in developmental psycholinguistics. In C. Ferguson \& D. Slobin (Eds.), Studies of child language development (pp. 485-97). New York: Holt, Rinehart \& Winston.

Smith, M. (1933). The influence of age, sex and situation on the frequency, form and function of questions asked by preschool children. Child Development, 4, 201-381.

Smith, C. (1970). An experimental approach to children's linguistic competence. In J. Hayes (Ed.), Cognition and the development of language (pp. 109-35). New York: Wiley.

Snow, C. (1972). Mothers' speech to children learning language. Child Development, 43, 549-65-

Soderbergh, R. (1974). The fruitful dialogue, the child's acquisition of his first language: Implications for education at all stages. Project Child Language Syntax, Reprint no. 2, Stockholm University, Institution for Nordiska Sprak.

Soskin, W. (1963). Verbal interaction in a young married couple. Lawrence: University of Kansas Social Science Studies.

Stern, D., Jaffe, J., Beebe, B., \& Bennett, S. (1975). Vocalizing in unison and in alternation: Two modes of communication within the mother- infant dyad. In D. Aronson \& R. Rieber (Eds.), Developmental psycholinguistics and communication disorders. Annals of the New York Academy of Sciences, 263, 89-100. 